\title{
Prevalence of Neck Pain in Relation to Gender, Posture and Ergonomics in Computer Users
}

\section{Mazhar Ali Bhutto ${ }^{1 *}$, Arsalan Abdullah ${ }^{2}$, Syed Asadullah Arslan ${ }^{3}$, M Sarfraz Khan ${ }^{4}$, Muhammad Khan Bugti $^{5}$ and Zeb Jehan Rana ${ }^{6}$}

${ }^{1}$ Tehran University of Medical Sciences - School of Rehabilitation, Iran

${ }^{2}$ Plastic Surgery and Traumatology, UK

${ }^{3}$ School of Rehabilitation, Tehran University of Medical Sciences, Iran

${ }^{4}$ Dow University of Health Science, Pakistan

${ }^{5}$ Physiotherapy Department, Shaheed Mohterma Benazir Bhutto Institute of Trauma, Pakistan

${ }^{6}$ Civil Hospital Mirpurkhas, Pakistan

*Corresponding Author: Mazhar Ali Bhutto, Physiotherapist, Schs Senior Specialist, Government of Sindh, Pakistan.

Received: August 06, 2019; Published: September 06, 2019

DOI: 10.31080/ASOR.2019.02.0097

\begin{abstract}
Objectives: To evaluate the incidence of neck pain in computer users, to create an awareness of contributing factors in Neck Pain. Introduction: Neck pain is very common amongst office workers who work continuously without any rest, proper posture, ergonomics and physical activities. Previous Studies showed that prolonged disuse of muscles and joints leads to stiffness in Neck muscles and they focused on implementation of Physical activity, In this study targeted the importance of Postural correction (Positioning) and ergonomically designed work-station in both genders. Our hypothesis was that females had less muscles power and are at risk compared to males; as the latter work harder for longer duration. We looked into the importance of posture and ergonomics and to get a better understanding, we evaluated the awareness of posture, ergonomics and their implementation during computer usage. We found that males suffered more neck pains than females. Ergonomics and Posture are almost equally important in preventing Neck Pain.

Methodology: Quantitative cross-sectional study was conducted amongst computer users (minimum 6 hours daily). Random Sampling Technique was used. Through using a Structured Questionnaire, 300 samples were collected and only 250 met the criteria of study. SPSS was used for calculations.

Results: Computer users in both gender considered in study Male 56\%, Female 44\%, participated. Symptomatic-population were $57 \%$, Those who felt neck pain were $67.9 \%$ male and $43.2 \%$ females. Amongst the symptomatic-population, $69 \%$ didn't follow and/ or were unaware about ergonomics and $62 \%$ adopted poor postures.

Conclusion: We found that males are at a greater risk compare to females. Our results showed that Poor posture and ergonomics are risk factors but the incidence of pain in more in latter.
\end{abstract}

Keywords: Neck Pain; Computer Users; Ergonomics; Posture

\section{Introduction}

Pain can be defined as unpleasant and unwanted sensation felt by the body under certain circumstances. An unpleasant sensation that can range from mild, localized discomfort to agony. Pain has both physical and emotional components. The physical part of pain results from nerve stimulation. Pain may be contained to a discrete 
area, as in an injury, or it can be more diffuse, as in disorders like fibromyalgia.

Regarding the Neck Pain, discomfort may come from contractile or non-contractile, such as nerves, discs, muscles capsules, ligaments, tendons, joints, etc. These all parts may lead to the stiffness and pain [1] in surrounding areas as well as being referred/radiating to the upper limb.

The Neck Pain is a subcategory of Muscular Skeletal Disorders (MSD) which includes muscles, nerves, tendons, joints, cartilages and discs. Whereas MSDs do not include traumatic or accidental disorders [2].

The Neck Pain in computer users is mostly common amongst office workers and is one of the major cause of absence from work thereby decreasing work productivity [3-5] and increasing the cost worldwide on the employees. It is believed that awareness about proper posture during computer use (Head in neutral position, Upper back and Lower back properly supported, the arm should be resting on the support with comfortable grip on the mouse) is very important.

Another factor for Neck Pain in computer users can be defined as ergonomically designed table and chairs [6] as suggested by NIOSH. The interaction between body posture and ergonomically designed system is key factor to reduce the occurrence of pain in computer users. The stiffness in muscles is believed to be due to overuse, lack of strength, improper use of muscles (odd posture) and without proper breaks/pauses during the continuous work.

Another opinion about muscle strength is believed that females have less muscular strength as compared to the males [7], that's why they have less ability to work continuously for longer durations. They thereby require more safely measures to minimise the chances of stiffness and pain in neck during computer usage.

In many of the previous studies, the focus was on the duration of computer usage, psychological factors, pathological factors and do not emphasise on gender, postures and ergonomics factors to identify their influence on Neck pain amongst computer users. This study was supposed to target the prevalence of these elements.

\section{Methodology}

We distributed 300 questionnaires, amongst people who are frequent computer users (such as those who work at Administration departments, Information Technology departments, Banks etc), to conduct a quantitative observational, cross-sectional study with purposive sampling technique. A modified version of "Dutch Musculoskeletal Questionnaire" was used, which contained personal information and work-related questions, to meet our criteria. Only 250 samples (were suitable for our study) which include minimum 6 hours of daily (continuous) computer use. In both gender, age between 20 years to 30 years were selected. The data was analysed on SPSS software and the mean, median, mode, standard deviation and percentages were calculated. We focused on the comparison of male and females, awareness of proper ergonomics and body posture.

\section{Results}

Amongst two hundred and fifty (250) participants, 56\% of them were males and $44 \%$ were females. Out of these total targeted populations, $57 \%$ were suffering from the symptoms and signs of neck pain. In male population, $67.9 \%$ reported neck pain whereas $43.2 \%$ of the females mentioned the same complaints. When we compared the awareness about the ergonomic system, $69 \%$ of the symptomatic population were unaware of its importance and/or were not following/implementing it according to the standard recommendations; whereas $62 \%$ of affected population were either not aware about the importance of good posture or were not following the recommended guidelines.

Following are the graphical and mathematical representations of the results:

\begin{tabular}{|l|c|c|}
\hline Gender & Frequency & Percentage \\
\hline Male & 140 & $56.0 \%$ \\
\hline Female & 110 & $44.0 \%$ \\
\hline Total & 250 & $100 \%$ \\
\hline
\end{tabular}

Table 1: Percentage of Male and Female Participant. 


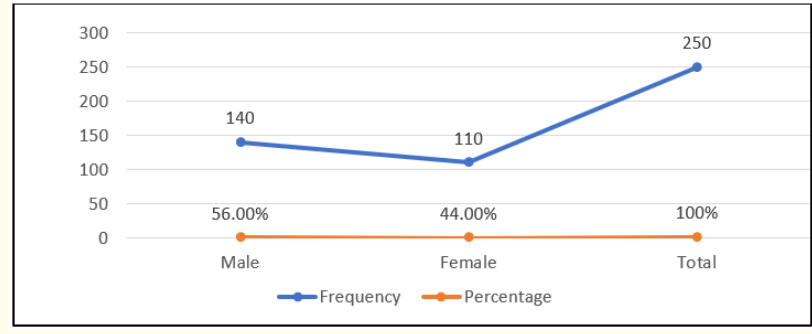

\begin{tabular}{|l|c|c|}
\hline Gender & Symptomatic Frequency & Percentage \\
\hline Male & 95 & $67.9 \%$ \\
\hline Female & 48 & $43.2 \%$ \\
\hline Total & 143 & $100 \%$ \\
\hline
\end{tabular}

Table 2: Symptomatic Genders.

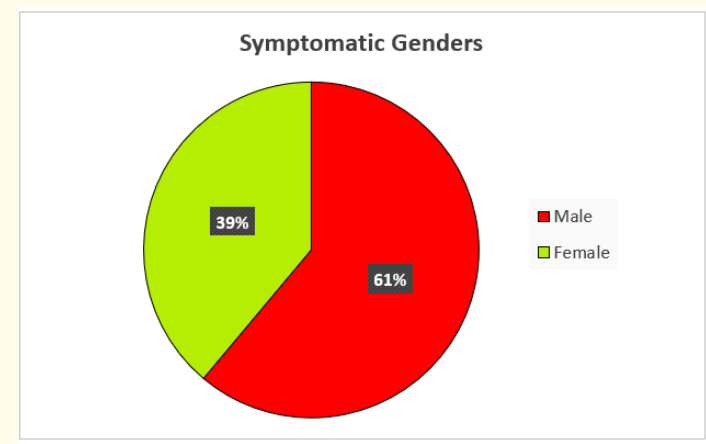

\begin{tabular}{|l|c|c|}
\hline Good Posture & Frequency & Percentage \\
\hline Yes & 95 & $38.0 \%$ \\
\hline No & 155 & $62.0 \%$ \\
\hline Total & 250 & $100 \%$ \\
\hline
\end{tabular}

Table 3: Awareness and Implementation of Correct Posture (while using a computer).

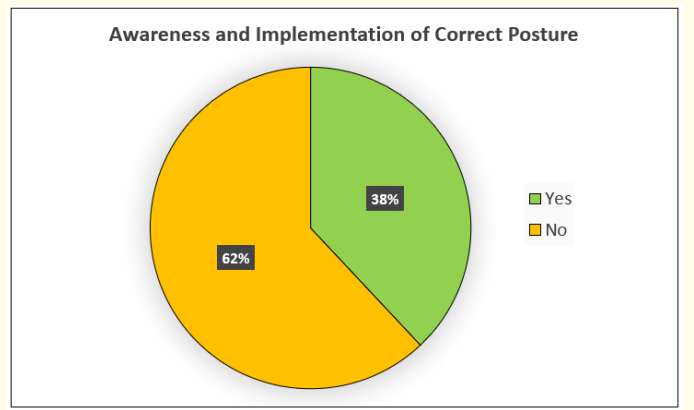

\begin{tabular}{|l|c|c|}
\hline $\begin{array}{l}\text { Ergonomically-Designed } \\
\text { Workstation }\end{array}$ & Frequency & Percentage \\
\hline Yes & 173 & $30.8 \%$ \\
\hline No & 77 & $69.2 \%$ \\
\hline Total & 250 & $100 \%$ \\
\hline
\end{tabular}

Table 4: Awareness and Implementation Ergonomically Designed WorkStation.

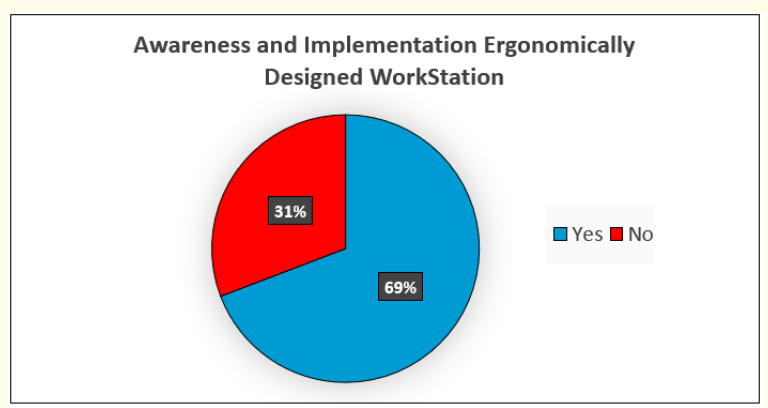

\section{Discussion}

Some of the previous studies about the prevalence of Neck pain in computer users showed variable results like in $2002,28 \%$ of the working population of Dutch were having the signs and symptoms of Neck Pain (either localised or radiating in nature) [8]. Another study about Neck Pain noted that $17 \%$ of 16 years olds youngsters had been complaining of recurrent pain in the neck [9]. Likewise, the study which showed results of $22 \%$ of 12 years old children felt Neck Shoulder Pain [10]. One more study conducted in Europe on work-associated problems in Neck and Shoulder, the result was $25 \%$ of the population complained about Neck Pain [11].

In the light of the above studies, we decided to conduct a study to find out the prevalence of Neck Pain amongst the young population of Pakistan, between the ages of 20 years to 30 years, and we found that $57 \%$ of the population were suffering from Neck Pain and stiffness with prolonged computer usage. This difference in results/percentages may be due to socio-economic conditions, lack of physical activity (sedentary lifestyle) and/or maybe due to extra work burden and stress.

Another parameter which we took in consideration was the effect of gender in Neck Pain with overuse of computers because few studies previously conducted were showing different results as in the study of adolescents, prolonged Neck and Shoulder Pain were $5 \%$ with more occurrence in females as compared to males [7]. 
Many researches quoted that working females are at a greater risk for Neck Pain as compared to males [12-14].

In comparison to the above-mentioned studies, our results were different as $67.9 \%$ of male were suffering from signs and symptoms as compared to the female population which was $43.2 \%$ (symptomatic cases). This variation in our study was may be due to the fact that in our society all heavy and prolonged work are being done by the males. Another reason could be due to working hours differences in both gender i.e males work longer hours (up to more than 10 hours daily) as compared to the female.

According to O'Sullivan 2006 there is marked difference in gender, usually in younger age the female sit with an erect posture as compared to males. Another study reported that when female and male, observed together in a group, it was found that all the symptomatic females were having similar posture. It was believed that this result was because of Cervico-Thoracic Posture or it was associated with habitual flexion of head in females [7]. In one study, it was described as chronic patient with Neck Pain showed significant changes in muscle functioning during performing an activity compared to the normal asymptomatic subjects [15]. Comparison with the postural effect studies, our results showed that there is huge effect of body positioning and support (while using the computer) as around $62 \%$ of the population were suffering from Neck Pain because of not following recommended postural guidelines for using a computer. It was likely to be the secondary effect of muscle fatigue due to using the computer in an improper position or as some studies suggests that lack of mobility leads to stiffness.

It has been suggested that the machines and materials are the apparatuses which makes our life easier and comfortable that is why we can count the work-station materials as helping tools to perform the work smoothly and efficiently. The proper use of working-tools at work-station like chairs and tables during computer use can help us to minimise the chance of harm and hazards from the prolonged computer usage. As many research studies conducted on ergonomically-designed work-station were of the opinion that ergonomics play an important role in improving productivity and creating a positive psychosocial behaviour [16]. It also prevent positioning faults and helps in keeping our body in a normal alignment. In our study, we have reached a conclusion that poor ergonomics have been affecting $69 \%$ of the symptomatic population which could contribute as a major risk factor during computer use.

\section{Conclusion}

The results acquired from our study reveals that males are mostly affected by the Neck Pain. The causes amongst both genders can be either due to improper working environment and improper positioning. The adjustment of posture and improving work-tools according to the work environment can prevent many possible problems. It is suggested that awareness programs regarding health and safety measures during work should be taught to the general public to cause a possible decline in work-related health issues.

\section{Bibliography}

1. Gross JM., et al. "Musculoskeletal examination”. John Wiley and Sons (2015).

2. Piedrahita H. "Costs of work-related musculoskeletal disorders (MSDs) in developing countries: Colombia case". International Journal of Occupational Safety and Ergonomics 12.4 (2006): 379-386.

3. Strong LL and FJ Zimmerman. "Occupational injury and absence from work among African American, Hispanic, and nonHispanic White workers in the national longitudinal survey of youth". American Journal of Public Health 95.7 (2005): 12261232.

4. Bernaards CM., et al. "The (cost-) effectiveness of a lifestyle physical activity intervention in addition to a work style intervention on the recovery from neck and upper limb symptoms in computer workers". BMC Musculoskeletal Disorders 7.1 (2006): 80 .

5. Jensen C. "Development of neck and hand-wrist symptoms in relation to duration of computer use at work". Scandinavian Journal of Work Environment and Health 29.3 (2003): 197-205.

6. Juul-Kristensen B and C Jensen. "Self-reported workplace related ergonomic conditions as prognostic factors for musculoskeletal symptoms: the "BIT" follow up study on office workers". Occupational and Environmental Medicine 62.3 (2005): 188-194.

7. Straker LM., et al. "Relationships between prolonged neck/ shoulder pain and sitting spinal posture in male and female adolescents". Manual Therapy 14.3 (2009): 321-329.

8. Heinrich J and B Blatter. "RSI-klachten in de Nederlandse beroepsbevolking”. TSG-Tijdschrift voor Gezondheidswetenschappen 83.1 (2005): 16-24.

9. Ming ZM Närhi and J Siivola. "Neck and shoulder pain related to computer use". Pathophysiology 11.1 (2004): 51-56. 
10. El-Metwally A., et al. "Prognosis of non-specific musculoskeletal pain in preadolescents: a prospective 4-year follow-up study till adolescence". Pain 110.3 (2004): 550-559.

11. De Kraker H and B Blatter. "Prevalentiecijfers van RSI-klachten en het voorkomen van risicofactoren in 15 Europese landen". Tijdschrift voor gezondheidswetenschappen 83.1 (2005): 8-15.

12. Östergren PO., et al. "Incidence of shoulder and neck pain in a working population: effect modification between mechanical and psychosocial exposures at work? Results from a one year follow up of the Malmö shoulder and neck study cohort". Journal of Epidemiology and Community Health 59.9 (2005): 721-728.

13. Gerr F., et al. "A prospective study of computer users: I. Study design and incidence of musculoskeletal symptoms and disorders". American Journal of Industrial Medicine 41.4 (2002): 221-235.

14. Korhonen T., et al. "Work related and individual predictors for incident neck pain among office employees working with video display units". Occupational and Environmental Medicine 60.7 (2003): 475-482.

15. Szeto GPY., et al. "Neck-shoulder muscle activity in general and task-specific resting postures of symptomatic computer users with chronic neck pain". Manual Therapy 14.3 (2009): 338-345.

16. Cagnie B., et al. "Individual and work related risk factors for neck pain among office workers: a cross sectional study". European Spine Journal 16.5 (2007): 679-686.

Volume 2 Issue 10 October 2019

(c) All rights are reserved by Mazhar Ali Bhutto., et al. 